Opinion

\title{
Huawei Unveils Huawei Mate X Foldable 5G Smartphone
}

\author{
George Zhuang* \\ Department of History, University of Florida, USA
}

*Corresponding author: George Zhuang, Department of History, University of Florida, USA.
Received Date: July 01, 2019

Published Date: July 02, 2019

\section{Opinion}

Hot on the heels of its South Korean-based competitor, Huawei announced its plans to release a foldable 5G-capable smartphone just four days after Samsung revealed its own foldable phone at an Unpacked press conference in San Francisco. This is Huawei's latest attempt to innovate and expand its earnings. In addition to staying ahead of the industry through R\&D, an essential part of any company's game plan, Huawei faces, as all smartphone manufacturers face, declining smartphone sales due to "[a] general market saturation of mobile computing devices. A slowing global economy, with rising trade tariffs ... And a final key factor may be the rising price of phones, like Apple's \$1,000 iPhone XS, that are prompting owners to wait longer between upgrades [1]”. Because of this global slowdown of smartphone purchases, Huawei and other smartphone manufacturers are forced to release new, and more innovative phones to make buying a new smartphone more appealing to consumers (Figure).

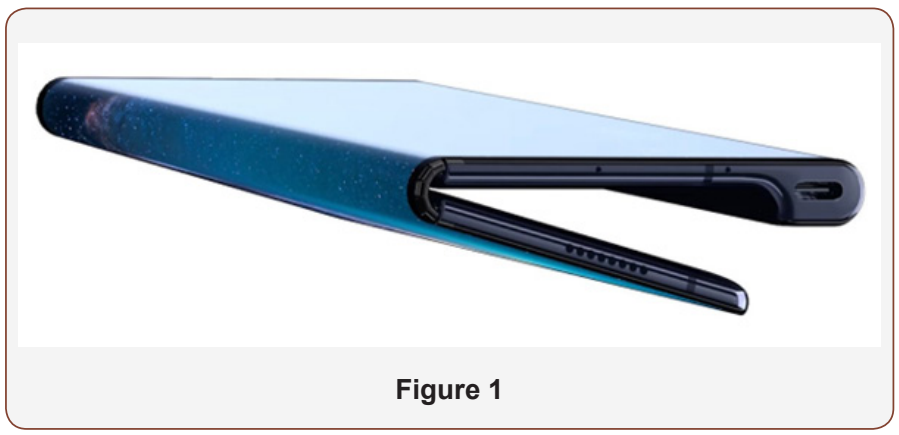

However, innovation does not come cheap, as Samsung and Huawei both made very clear with their initial price points for their foldable phones, the Galaxy Fold and Huawei Mate X, respectively. The Galaxy Fold (4G version) was priced at just under $\$ 2,000$, at $\$ 1,980$, while the $5 \mathrm{G}$ (standard) Huawei Mate $\mathrm{X}$ was priced at a whopping $\$ 2,600$. Though simply looking at face value, the Huawei Mate X looks like it is very much overpriced compared to the Galaxy
Fold, Ars Technical mentions that "the two devices are not quite comparable. The nearly \$,2000 [sic] Galaxy Fold price tag is for the $4 \mathrm{G}$ version, while the Mate $\mathrm{X}$ comes standard with $5 \mathrm{G}$, not to mention the bigger display." According to the same source, "The Fold will have a $5 \mathrm{G}$ version too, but we don't know how much it will cost [2]". Comparatively, Apple's flagship iPhone XS, was priced, starting out at $\$ 1,000$, nearly half the price of the Fold. It is interesting to note, too, that Samsung and Huawei were not the only companies to have developed a foldable phone. Royole's FlexPai released earlier this year, which claimed to be the world's first foldable smartphone

[3]. The phone itself doesn't look nearly as good as the Fold or Mate $\mathrm{X}$, but it has the advantage of being much cheaper than those of its competitors. It also demonstrates that giants of industry don't have a monopoly on innovative design.

Now, whether this foldable design will take off will depend on three things. Firstly, the global economy: can people afford to buy such expensive phones? Secondly, whether, and to what degree, they will increase consumers' quality of life: are these phones' foldable screens just a gimmick or will they make life easier for its users? And thirdly, further innovation: how long will it be before another company releases a smartphone with a more innovative design?

Firstly, we must look at basic economics. Will people be able to afford such expensive devices, or will the vast majority of consumers simply be priced out? I am by no means an expert on economics, but I do know that a phone this expensive will require potential buyers to have a great deal of disposable income [4-6]. For many people, a device this expensive, especially one they already have (minus the foldable screen) will cost them a large portion of, if not their entire, paycheck for a whole month's work, even with an improving global economy. So right from the start, it appears that many people will be priced out completely. 
Which leads me to my next point. Will these foldable smartphones increase the consumer's quality of life? If so, to what degree? Will a bigger screen make life easier and more worth the money to the consumer? When considering this point, my thoughts were led instantly to the tablet. These phones are basically a 2-in-1 device, combining the capabilities of a smartphone with the bigger screen and accessibility of a tablet. Sure, tablets make things easier for the user, with their larger screen and all, but these smartphones, which have much less functionality, will be priced higher than a high-end computer or laptop. I suppose portability then, is what the consumer will be primarily paying for, but just how much is portability worth?

Lastly, we must consider further innovation. How long will this 'innovative' design last in an industry moving at a very, very rapid pace? This idea of a foldable smartphone sounds, to me, more like a pit stop along the road to further development and innovation. It seems more like an add-on than an entirely new product. The question is, will making this pit stop be worth it in the long run?

There is a lot to consider when looking at these 'new' smartphones, but the biggest question for the tech industry to consider is whether releasing foldable smartphones to boost earnings and slow, or even reverse, the trend of declining smartphone sales in the short term be worth it in the long run? I think that ultimately, it will be. This novel take on the smartphone should boost their sales in the short term, which should hold them over until they can create something truly innovative. Although I, personally, am not completely sold on this upcoming smartphone trend, I am certain that many others will buy into it. And that may not be so bad, as long as it leads to bigger and better things [7-9].

\section{Acknowledgement}

None.

\section{Conflict of Interest}

No conflict of interest.

\section{References}

1. Aaron Pressman (2018) Why Global Smartphone Sales Are About to Decline for the First Time Ever. TechSmartphones.

2. Ron Amadeo (2019) Move over Samsung, Huawei's foldable smartphone is an absolute stunner. Ars TECHNICA.

3. https://www.royole.com/flexpai

4. https://www.apple.com/shop/buy-iphone/iphone-xs

5. https://bgr.com/2019/02/20/galaxy-fold-release-date-gets-closerleaked-images-show-final-design/

6. Richard Yu (2019) Huawei announces folding 5G smartphone. Technology.

7. https://www.channelnewsasia.com/news/technology/samsunglaunches-folding-smartphone-galaxy-fold-firs..

8. https://consumer.huawei.com/en/phones/mate-x/

9. https://www.samsung.com/global/galaxy/galaxy-fold/ 